\title{
CONSTRUFIG3D: Uma Ferramenta Computacional para apoio ao ensino da Geometria Plana e Espacial
}

\author{
Jorge Luís de Souza Mendes - Universidade Severino Sombra - Vassouras - RJ \\ Janaina Veiga Carvalho- Universidade Severino Sombra - Vassouras - RJ \\ jvc@uss.br \\ Carlos Vitor de Alencar Carvalho- Universidade Severino Sombra - Vassouras - RJ \\ cvac@uss.br
}

\section{Resumo}

Este trabalho apresenta o desenvolvimento de um sistema computacional para apoio ao ensino da geometria plana e espacial chamado de CONSTRUFIG3D. Trata-se de um software livre e código aberto, de interface bastante simples que permite a composição e visualização de figuras espaciais a partir de figuras planas selecionadas pelo aluno. Desenvolvido para alunos que estão iniciando o estudo da geometria, o CONSTRUFIG3D auxilia na identificação das figuras planas e espaciais. O sistema desenvolvido é bastante interativo, possibilitando aos alunos uma postura dinâmica em relação à aprendizagem e composição de figuras espaciais.

Palavras-chave: Educação Matemática, Software Livre, Computação Gráfica Aplicada, Geometria Plana e Espacial.

\section{CONSTRUFIG3D: Computational tools for the teaching of Plane and Spatial Geometry}

\begin{abstract}
This work presents the development of the software CONSTRUFIG3D for support to the teaching of $2 \mathrm{D}$ and 3D geometries. It is freeware software, with a simple interface that it allows the composition and visualization of 3D figures starting from the selection of 2D geometries by the students. It developed for students that are beginning in the study of the geometry, the CONSTRUFIG3D aids in the identification of the 2D and 3D geometries. The developed system is quite interactive, facilitating to the students a dynamic posture in relation to the learning and composition of $3 \mathrm{D}$ geometries.
\end{abstract}

Key-Words: Mathematic Education, Freeware Software, Computer Graphics Applied, Plane and Spatial Geometry.

\section{Introdução}

A utilização da informática como apoio ao processo ensino-aprendizagem é sem dúvida um grande e interessante desafio. Nos dias atuais esta perpectiva não pode mais se ignorada pelas escolas, uma vez que tais tecnologias são instrumentos que possuem um grande potencial pedagógico para os professores. Esta tecnologia pode ser implementada através de sistemas computacionais com enfoque educativo.

Um sistema computacional educativo é todo sistema que tem o objetivo de melhorar o processo ensino-aprendizagem de um conteúdo ou assunto educacional.

Com ele pode-se: aumentar o crescimento intelectual do aluno; despertar a curiosidade e tornar as aulas mais dinâmicas e interessantes. Outra vantagem e a 
possibilidade do estudo dos assuntos ministrados em horários e locais diferentes da sala de aula, bastando para isto ter acesso a um computador.

Segundo Valente (1993), um programa computacional educativo, pode estar inserido em uma das seguintes categorias:

- Sistemas tutoriais: O conteúdo a ser ensinado é dividido em pequenas partes (módulos), que apresentam animações, som, vídeos.

- Sistemas de exercícios e práticas: São usados para revisar o material visto em sala de aula, envolvem memorização e repetição. Geralmente o aluno deve indicar a sua resposta para depois verificar se está certa ou errada e refletir sobre a resposta.

- Simulações: Permite a criação de um modelo simplificado, reduzido onde várias situações, sobre um determinado assunto, podem ser exploradas. A simulação oferece a possibilidade do aluno desenvolver hipóteses, testá-las, analisar resultados e refinar os conceitos.

- Jogos educacionais: A pedagogia por trás desta abordagem é a de exploração auto dirigida ao invés da instrução explícita e direta. A proposta defende que as crianças aprendem melhor quando ela é livre para descobrir relações, ao invés de ser ensinada.

No ensino da geometria, foco deste artigo, essas ferramentas podem ser pesquisadas e desenvolvidas utilizando técnicas da Computação Gráfica (Foley et al., 1999). Tais técnicas tem o objetivo de auxiliar na melhor percepção de conjunto de dados, descrever ambientes e visualizar processos e simulações através de animações, gráficos, desenhos $2 \mathrm{D}$ e 3D.

Gladcheff, Zuffi \& Silva (2001) consideram que os sistemas computacionais educativos para a matemática no ensino fundamental têm os seguintes objetivos: ser fonte e informação, auxiliar o processo de construção de conhecimentos, desenvolver a autonomia do raciocínio, da reflexão e da criação de soluções.

Este trabalho mostra o desenvolvimento de um sistema educativo, chamado de CONSTRUFIG3D. Trata-se de um sistema que utiliza a abordagem de um jogo/simulação onde o aluno desenvolve conceitos sobre a construção de figuras espacial a partir de figuras planas. Com interface bastante simples, ele utiliza conceitos da Computação Gráfica, com área de trabalho 2D e 3D e permite rotacionar a figura espacial criada, bem como mostrar suas características: vértices, arestas e faces.

\section{Desenvolvimento computacional}

Para o desenvolvimento do CONSTRUFIG3D, inicialmente precisou ser definido quais e quantas figuras planas poderiam ser utilizadas pelos usuários para tentar montar uma figura espacial. Para uma versão inicial do sistema optou-se, pelas figuras mostradas na Tabela 1 na quantidade mínima de três e no máximo seis. A Tabela 1 mostra também os seus identificadores que têm o objetivo de auxilar no algoritmo de determinação da figura espacial. Para facilitar a visualização por parte do usuário, cada figura plana é desenhada com uma cor diferente como mostra a Figura 1. 
A escolha das figuras planas que serão usadas para compor a figura 3D é feita de forma livre. O sistema foi preparado para considerar todos os casos selecionados pelo usuário em qualquer ordem. Por exemplo, para montar um cilindro o aluno pode escolher: um retângulo e dois círculos; um círculo, um retângulo e um círculo; dois círculos e um retângulo. A Figura 2 mostra alguns exemplos.

Tabela 1: Identificados das figuras planas.

\begin{tabular}{|c|c|}
\hline Código & Figura plana \\
\hline 01 & Círculo \\
\hline 02 & Retângulo \\
\hline 03 & Triângulo \\
\hline 04 & Quadrado \\
\hline
\end{tabular}
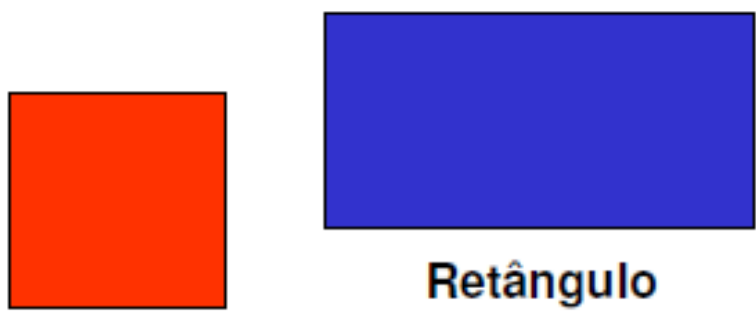

Retângulo

\section{Quadrado}
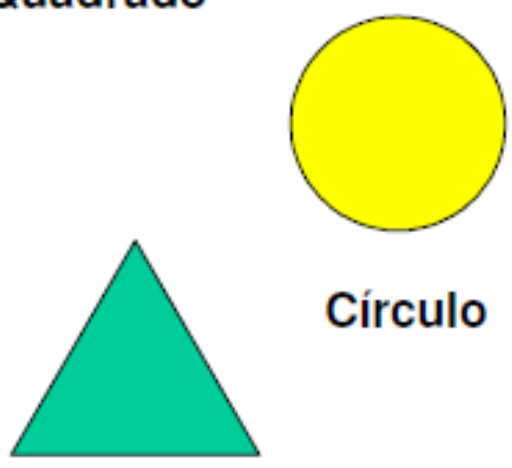

Círculo

Triângulo

Figura 1 - Definição das figuras planas. 

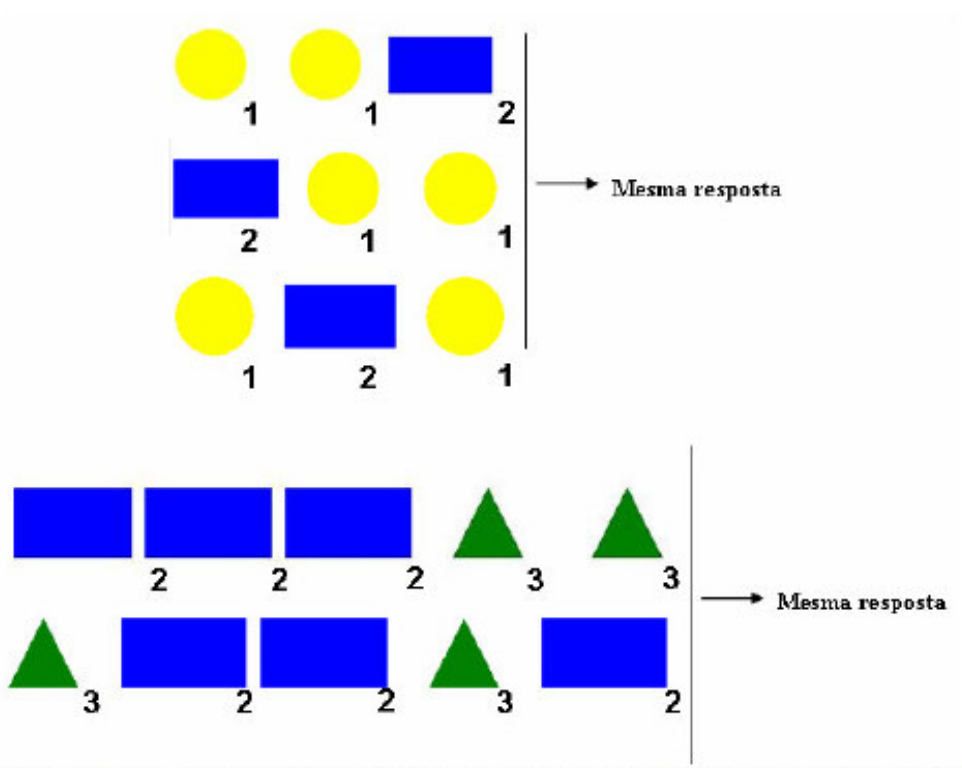

Figura 2: Exemplos de sequências diferentes que chegam à uma mesma figura espacial.

Se a quantidade e as figuras planas selecionadas forem coerentes, uma figura espacial será montada e visualizada. Resumidamente o usuário deve seguir as seguintes etapas:

- Selecionar o número de 3 a 6 conforme quantidade de faces da figura espacial desejada;

- Selecionar as figuras planas que compõem a figura espacial. Na área de desenho 2D aparecerá as figuras conforma seleção;

- Em seguida acionar o botão montar;

- Se a sequência e a quantidade for correta aparecerá a figura desejada na área de desenho 3D e uma mensagem associada a montagem da figura espacial, caso contrário uma mensagem aparecerá avisando que a figura não pode ser montada.

A implementação descrita acima foi feita em linguagem $C$, utilizando o sistema de interface IUP (Levy,1996) e o sistema gráfico OpenGL (Woo et al.,1999). Todas as bibliotecas utilizadas são de código aberto e livro uso. Esta é uma outra abordagem e característica importante deste sistema, uma vez que nos dias atuais, os custos envolvidos com o licenciamento de programas tornaram-se proibitivo para a maioria das instituições. Deve-se ressaltar também que a pesquisa e o desenvolvimento de sistemas computacionais, em contrapartida à compra de sistemas comerciais, contribuem significativamente para o desenvolvimento tecnológico.

\section{Resultados}

A interface do sistema desenvolvido pode ser visualizada na Figura 3. Pode-se identificar uma área 2D e 3D para a visualização das figuras planas e espaciais respecitivamente além de uma barra de ferramentas. 


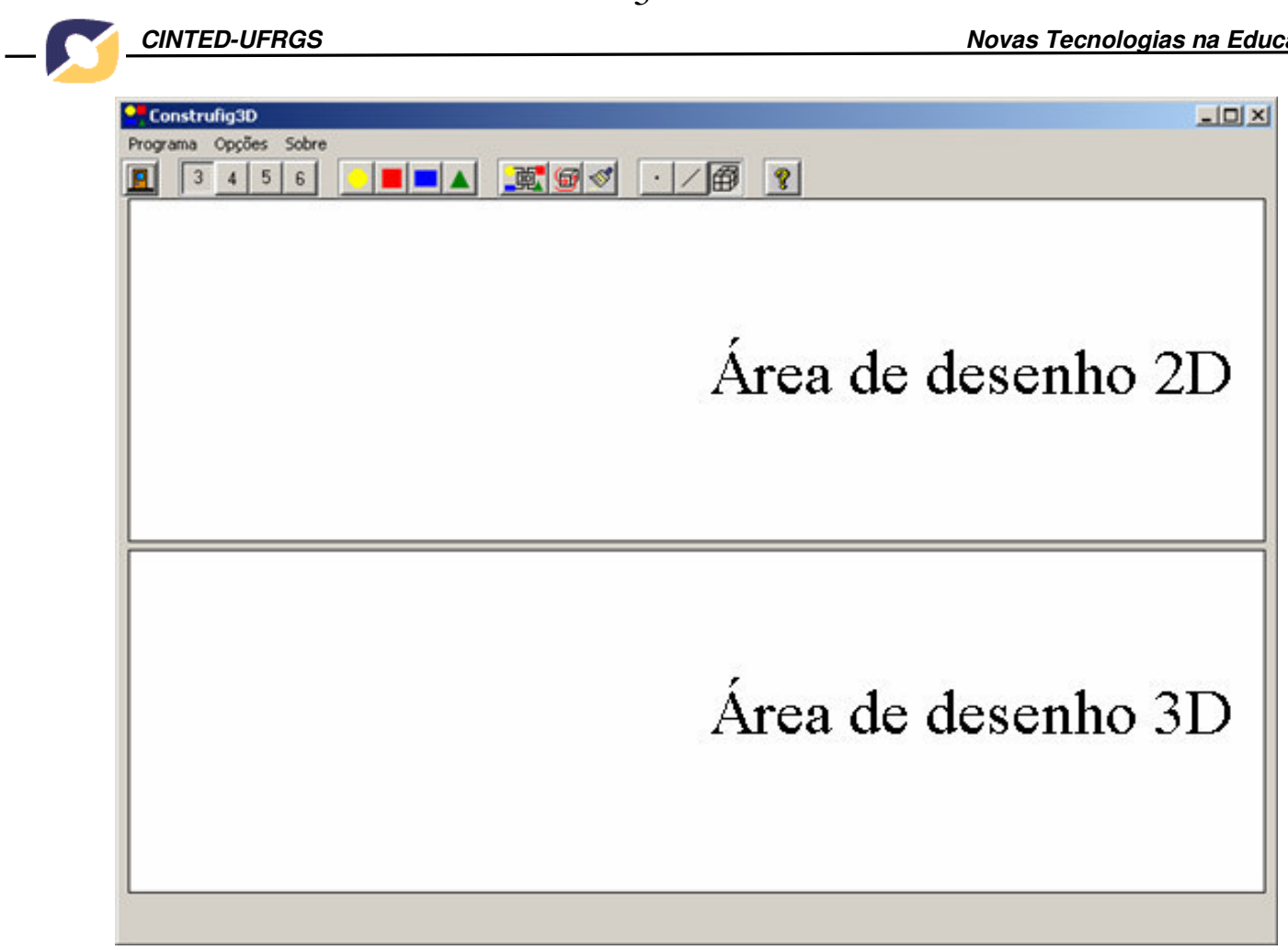

Figura 3: Interface do CONSTRUFIG3D.

A Figura 4 mostra a barra de ferramentas em detalhes. As suas principais funcionalidades são:

- Número de Figuras Planas: Aqui é escolhido o número de figuras planas, que serão usadas para montar a figura espacial. As figuras planas escolhidas serão mostradas na ordem do clique na área de desenho 2D. É necessário no mínimo de 3 e máximo de 6 figuras planas. Quando o número de figuras é modificado, todo processo é reiniciado.

- Figuras Planas: Aqui são escolhidas as figuras planas que serão usadas para montar a figura espacial. Figuras existentes: Círculo, Quadrado, Retângulo e Triângulo. Quando a quantidade de figuras escolhidas é igual ao número de figuras escolhidas, os botões ficam desabilitados.

- Montar: Quando acionado, verifica se é possível montar uma figura espacial com as figuras planas escolhidas. Sendo possível é desenhado a figura espacial na área de desenho 3D e será mostrado a mensagem correspondente a figura espacial montada. Senão for possível montar é exibida uma mensagem de erro.

- Rodar: Quando acionado, faz o movimento de rotação na figura espacial montada, para uma melhor visualização do usuário.

- Vértices: Quando acionado, identifica os vértices da figura espacial montada.

- Arestas: Quando acionado, identifica as arestas da figura espacial montada, desde que as faces estejam desmarcadas.

- Faces: Quando acionado permite retirar ou preencher as fases da figura espacial formada, permitindo uma melhor visualização das arestas e vértices.

- Limpar: Quando acionado, reinicia o CONSTRUFIG3D, limpando as áreas de desenho e voltando a etapa inicial do processo de montagem das figuras.

- Sobre: Quando acionado, mostra informações sobre o CONSTRUFIG3D, nomes e contato dos desenvolvedores e o site do projeto.

- Fechar: Quando acionado, fecha o aplicativo.

Figura 


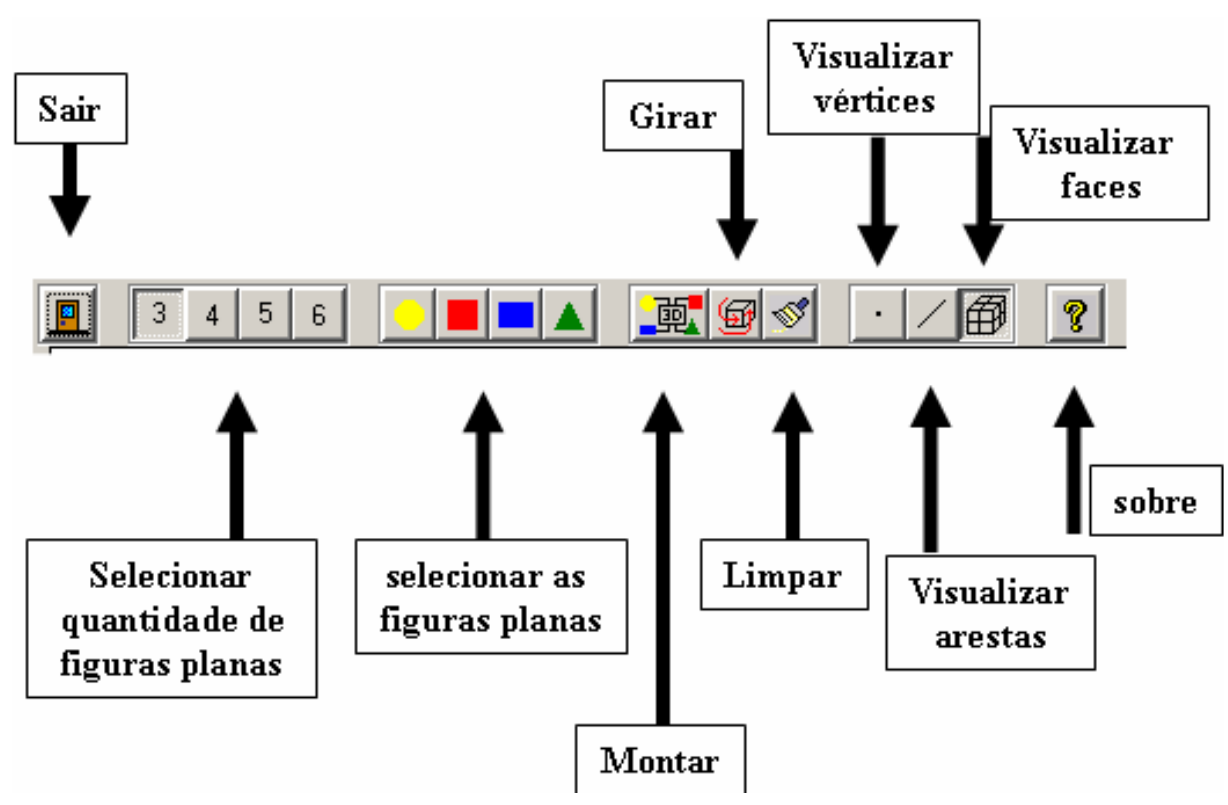

Figura 4: Barra de ferramentas do CONSTRUFIG3D.

A Figura 5 mostra a mensagem exibida quando o aluno não consegue montar a figura espacial com as figuras planas que ele escolheu.

Năo é possivel montar uma figura espacial com as figuras planas escollidas!!!

Figura 5: Mensagem quando a figura espacial não é montada.

A Figura 6 mostra a mensagem exibida quando o aluno tentar montar uma figura $3 \mathrm{D}$ sem selecionar uma figura $2 \mathrm{D}$.

Vocé ainda năo escolheu nenhuma figura planal!!

Figura 6: Mensagem quando nenhuma figura plana é selecionada.

A Figura 7 mostra a mensagem exibida quando o aluno consegue montar a figura $3 \mathrm{D}$.

Vocé montou um Tetraedro com: 4 Triângulos!!!

Figura 7: Mensagem quando uma figura espacial é montada.

As Figuras 8, 9, 10, 11 e 12 mostram algumas imagens do CONSTRUFIG3D em utilização. 
Programa Opgōes Sobre

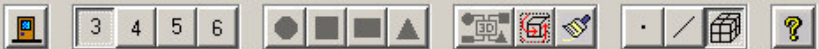

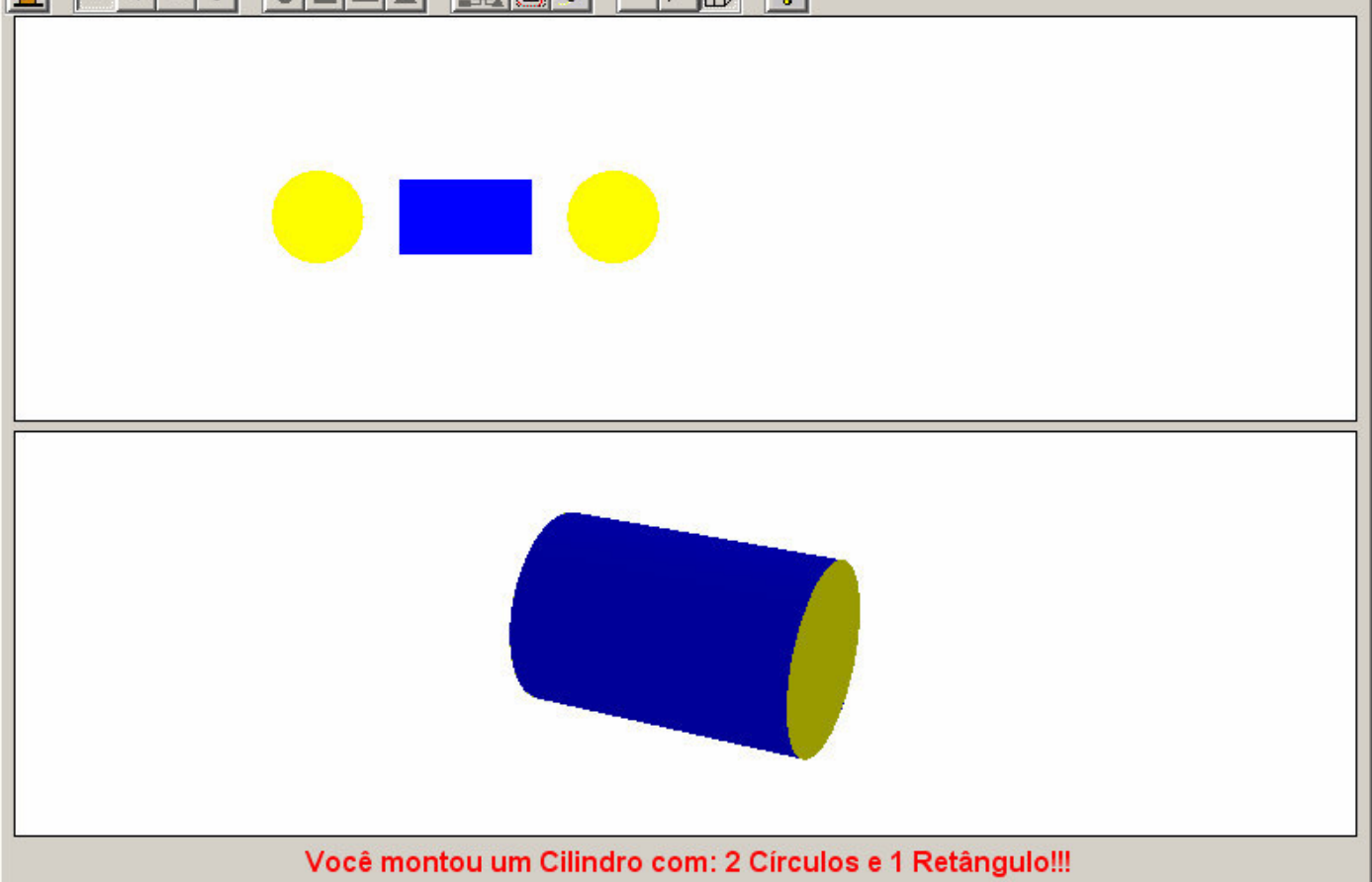

Figura 8: Figuras planas escolhidas pelo usuário e o cilindro montado e visualizado na área 3D. 


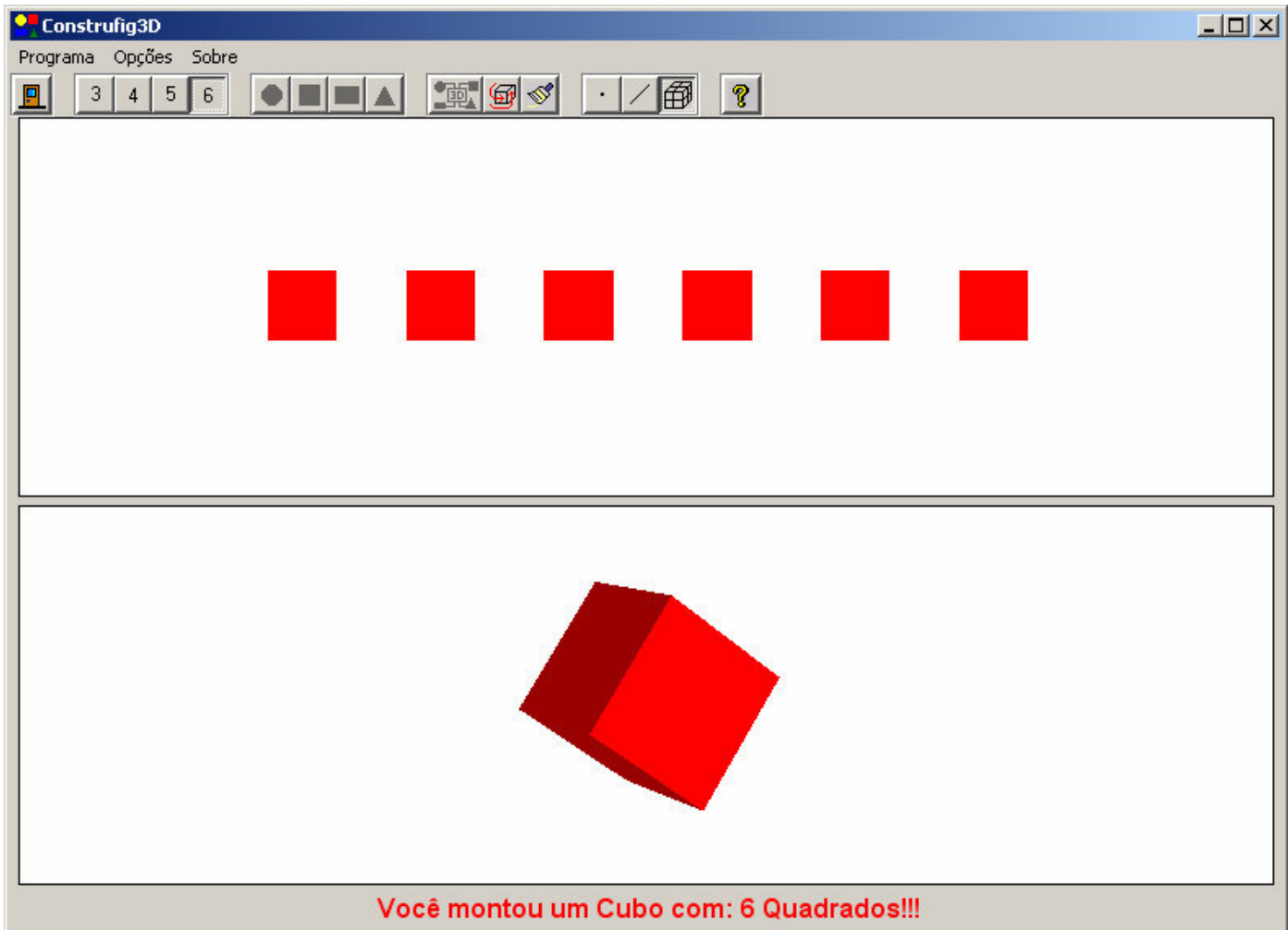

Figura 9: Figuras planas escolhidas pelo usuário e o cubo montado e visualizado na área 3D.

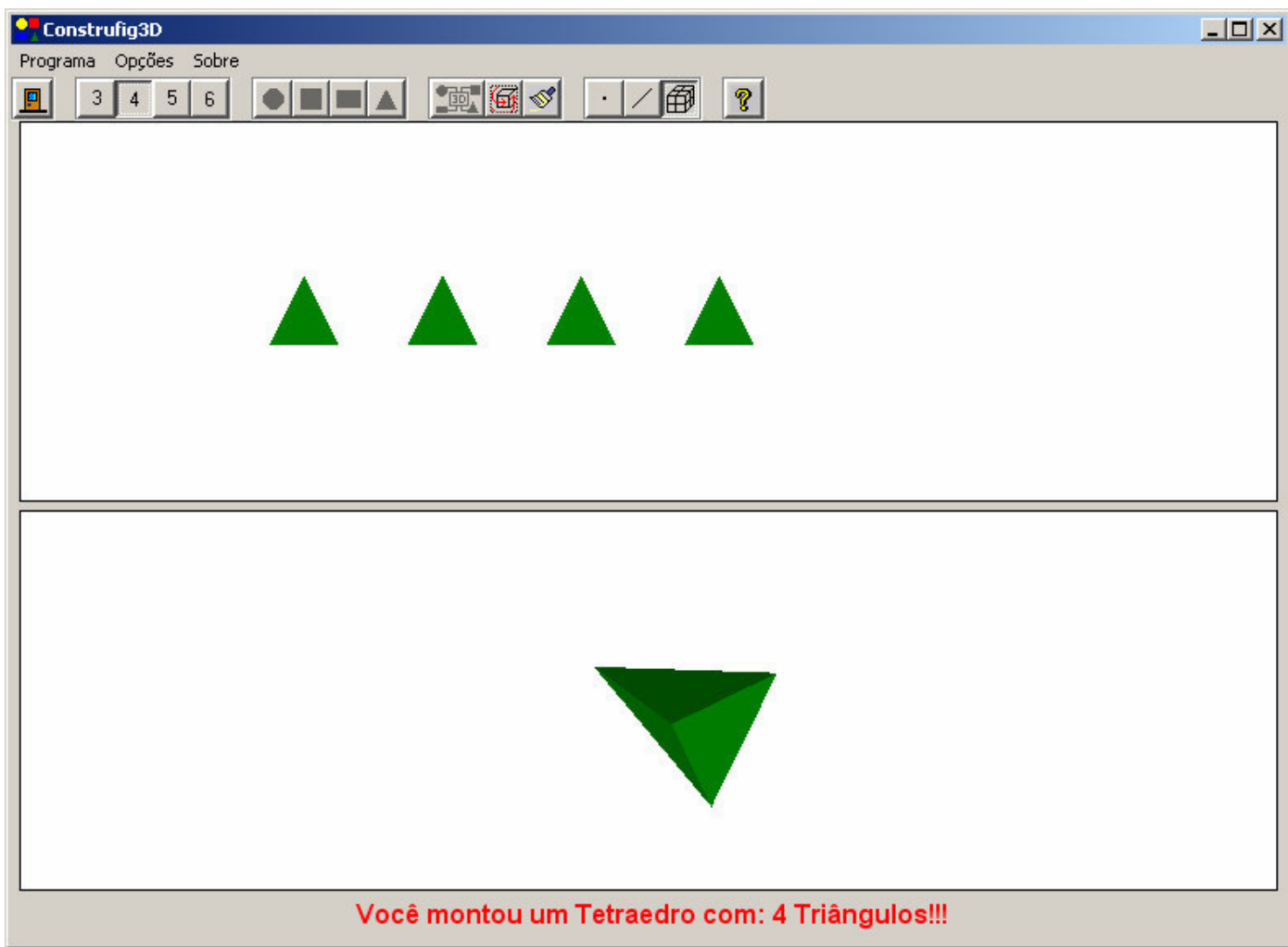

Figura 10: Figuras planas escolhidas pelo usuário e o tetraedro montado e visualizado na área 3D. 


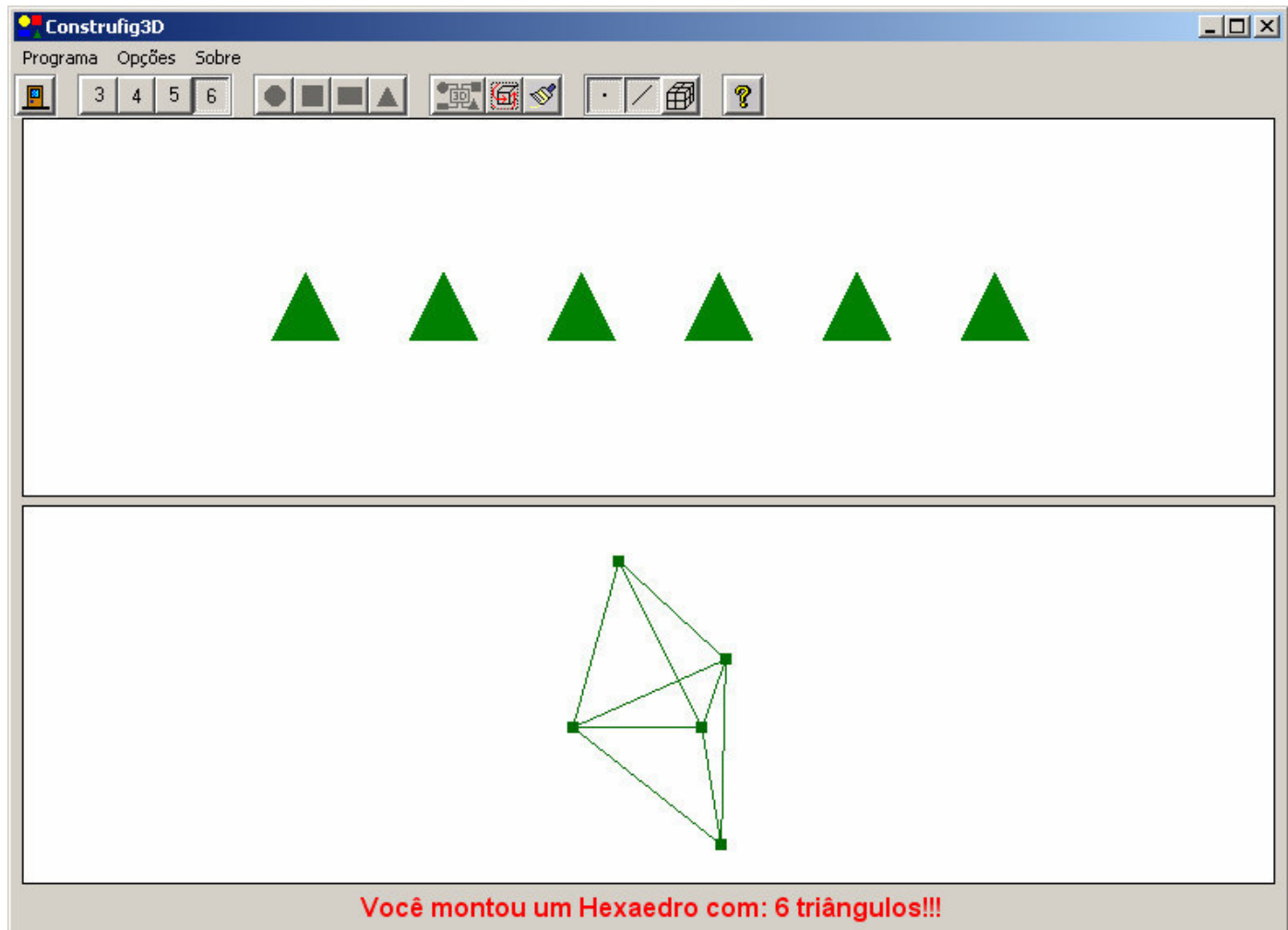

Figura 11: Figuras planas escolhidas pelo usuário e o hexaedro montado e visualizado na área 3D através de seus vértices e arestas.

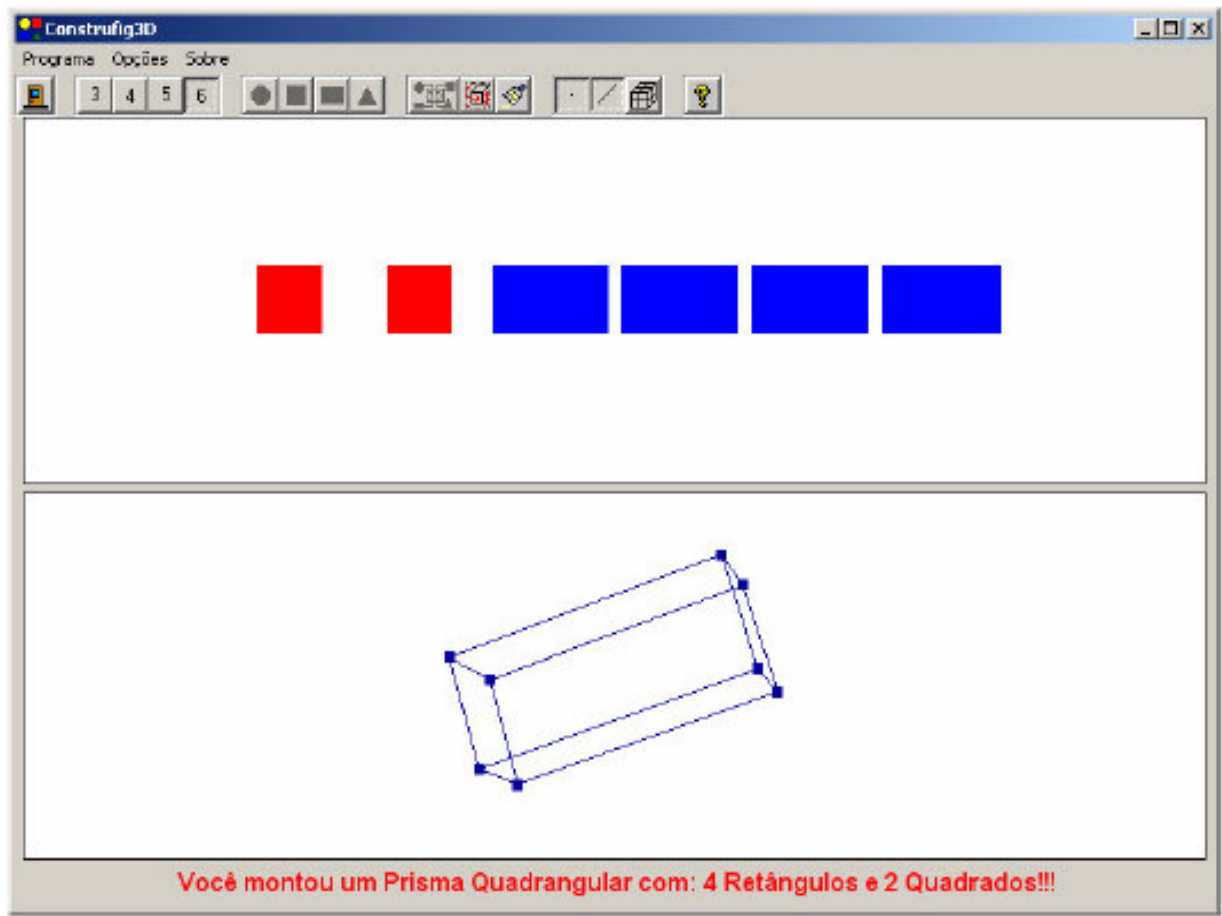

Figura 12: Figuras planas escolhidas pelo usuário e o Prisma Quadrangular montado e visualizado na área 3D através de seus vértices e arestas. 
Outras imagens, informações e o próprio aplicativo podem ser vistos e adquiridos no site: http://www.cvac.eng.br/ConstruFig3d/construfig3d.html.

\subsection{Sugestão de atividade prática}

Como uma primeira opinião sobre o sistema, o CONSTRUFIG3D foi utilizado em uma oficina (Nascimento et al., 2005) realizada no IV Encontro Sul-Fluminense de Educação Matemática (ESFEM), ocorrido em dezembro de 2005 na Universidade Severino Sombra (Vassouras/RJ). A oficina foi dividida em dois módulos. O primeiro com uma atividade prática e o segundo com a utilização do CONSTRUFIG3D. A idéia principal da atividade prática é possibilitar ao aluno a manipulação e construção de figuras espaciais antes da utilização deste sistema. Com está atividade, observou-se uma maior atenção e concentração do aluno e ainda auxiliou a ensinar os alunos a utilização do aplicativo uma vez que o mecanismo é o mesmo.

Assim, os alunos da oficina foram divididos em cinco sub-grupos (quatro integrantes cada sub-grupo). Cada grupo recebeu um kit de montagem (4 círculos, 10 retângulos, 10 quadrados, 10 triângulos e uma fita durex). Durante 25 minutos cada subgrupo tentou montar a maior quantidade de figuras espaciais. Após esta etapa cada grupo tentou reproduzir no CONSTRUFIG3D, em 20 minutos, o processo de montagem das suas figuras espaciais.

Foi observado o entusiasmo dos alunos para montar as figuras espaciais no CONSTRUFIG3D ocorrendo até uma competição de quem montava todos as figuras em menor tempo. Os alunos gostaram muito da idéia do sistema fazendo muitos elogios.

Fizeram algumas sugestões como incluir a visualização de vértices, arestas e faces (funcionalidades que já estão implementadas na versão atual). Também observou-se que dois grupos identificaram uma figura espacial que não estava implementada no sistema (o Hexaedro) e que posteriormente foi adicionada.

\section{Considerações Finais}

A utilização de ferramentas computacionais, como no caso do CONSTRUFIG3D, permitem ao professor observar como o assunto está sendo absorvido pelo aluno. Espera-se então, com este sistema aumentar o conteúdo assimilado pelo alunos e tornar as aulas mais dinâmicas. A primeira avaliação foi muito interessante e bem recebidas pelos alunos.

A próxima etapa, que já está sendo implementada, será utilizar o sistema com alunos do público alvo em um estabelecimento de ensino para verificar sua avaliação/validação. Será escolhida um turma que esteja iniciando os seus estudos sobre geometria plana e espacial para utilizar o CONSTRUFIG3D nas aulas. Após a utilização da ferramenta os alunos e o professor deverão responder um teste de aproveitamento sobre o CONSTRUFIG3D. O estudo deste instrumento de medida será utilizado, por exemplo, para melhorar as funcionalidades do aplicativo.

\section{Referências Bibliográficas}

FOLEY, J.D. and VAN DAM, A. and FEINER, S. K. and HEGHES, J. F. Computer Graphics Principles and Practice, second edition in C, Addison-Wesley publish 
company, 1999.

GLADCHEFF, A. P., ZUFFI, E.M. \& SILVA, M.da (2001) Um Instrumento para Avaliação da Qualidade de Softwares Educacionais de Matemática para o Ensino Fundamental, Anais doXXI Congresso da Sociedade Brasileira de Computação, 2001. NASCIMENTO, Antonio Sergio Alves, MENDES, Jorge Luis de Sousa, CARVALHO, Janaina Veiga, CARVALHO, Carlos Vitor de Alencar. PLOTFUNCAO e

CONSTRUFIG3D: Duas ferramentas gráficas e interativas para apoio ao ensino da matemática de funções e geometria plana e espacial. Oficina realizada no

Encontro Sul-Fluminense de Educação Matemática. Universidade Severino Sombra, 2005.

VALENTE, J. A. Diferentes Usos do Computador na Educação. Em J.A. Valente (Org.), Computadores e Conhecimento: repensando a educação (pp.1-23). Campinas, SP: Gráfica da UNICAMP, 2003.

WOO, M. and NEIDER, J. and DAVIS, T. and SHREINER, D, OpenGL

Programming Guide, Third Edition (OpenGL, Version 1.2), 800 p. Addison-Welsey, 1999. 